\title{
UNIVERSITY OF CINCINNATI: CASE STUDY OF ONLINE STUDENT SUCCESS
}

\author{
Melody Clark \\ Lisa Holstrom \\ Ann M. Millacci \\ University of Cincinnati
}

\begin{abstract}
The University of Cincinnati (UC) is a premier, public, urban research university dedicated to undergraduate, graduate, and professional education, experience-based learning, and research. The University also maintains a deep commitment to accessible education. Distance learning is an integral part of the University's 21st century approach to meeting diverse educational needs of students increasing access to high quality educational programs and offerings and meeting mounting workforce and student demands and expectations for customized curriculum, flexible delivery and use of 21st century technology.
\end{abstract}

UC has entire degree programs available online, as well as a variety of stand-alone distance learning courses, such as General Education courses. These courses are offered quarterly to serve students in distance learning programs, as well as students in on campus programs.

In a recent review UC students matriculated in online undergraduate degree programs (two associate and five baccalaureate degrees) taking 100 and 200 level courses during Autumn quarter 2008, it was noted that $85.15 \%$ of these learners successfully completed courses with a grade of C- or better for each course. The strategic framework of success is grounded in the University's academic strategic plan and commitment to provide quality learning experiences for all students. Noted are examples of strategies that align with Sloan-C Pillars of Success.

\section{KEYWORDS}

Student Success, Course Completion, Retention, Five Pillars

\section{INTRODUCTION}

The University of Cincinnati (UC) is a premier, public, urban research university dedicated to undergraduate, graduate, and professional education, experience-based learning, and research. Its strong commitment to excellence and diversity is seen in its students, faculty, staff, and all its activities. Within an inclusive environment, innovation and freedom of intellectual inquiry flourish. Through scholarship, service, partnerships, and leadership, the institution creates opportunity, develops educated and engaged citizens, enhances the economy and enriches the University, city, state and global community.

UC has achieved distinction through its nationally ranked programs, including the nation's top ten architecture, criminal justice, medicine, interior design, music and science programs. In addition to distinguished scholarship and research, the University maintains a deep commitment to accessible education. 
The University's academic strategic plan, UC|21: Defining the new Urban Research University (http://www.uc.edu/uc21) reflects the University's role as a leader in the 21st Century. Distance learning is an integral part of the University's 21st century approach to meeting diverse educational needs of students - increasing access to high quality educational programs and offerings and meeting mounting workforce and student demands and expectations for customized curriculum, flexible delivery and use of 21st century technology.

\section{INSTITUTIONAL COMMITMENT TO DISTANCE LEARNING}

UC's first distance learning program began in 1984 with the Open Learning Fire Science program via correspondence format. Other early adopters of distance delivery formats included colleges serving nontraditional, adult learners via a range of telecourses that combined independent study, video broadcasts and videotape with periodic face-to-face meetings. In Spring 2000 the University offered its first complete online degree program, the Associate in Applied Science (AAS) in Early Childhood Education. Currently, UC offers 15 online degree programs spanning six UC colleges and includes two associate, five baccalaureate, seven master's, and one doctorate [PharmD].

Of the more than 37,000 students enrolled at the University of Cincinnati in autumn 2008, over 2,800 students were enrolled in online programs. The majority (87\%) of these online students are part-time and female (78\%) with an average age of 34.5. These students are from all 50 states and originate from more than 36 countries, with the highest number of international students reporting they are Canadian citizens.

In addition to these online degree programs, a variety of stand-alone online courses are offered on a quarterly basis, such as online General Education courses. These courses serve students in distance learning programs, as well as students in on campus programs.

\section{ACADEMIC PERFORMANCE AND STUDENT SUCCESS}

Many online programs at the University of Cincinnati boast high retention rates with some reporting higher rates than their on-campus counterparts. Students pursuing online degrees tend to perform well academically and successfully complete online courses at a high rate.

Data presented here were collected during autumn quarter 2008. Grades were evaluated from all students enrolled in 100-level and 200-level on campus and online courses to determine success rates for these undergraduate learners. To determine student success, only grades of C- or better were used. Students who withdrew without completing a course or received a grade of D, F, or Incomplete were not considered successful. For purposes of this report, data for students enrolled for Pass/Fail credit were not considered.

In a review of grade distribution in on-campus 100 and 200 level courses during autumn 2008 (83,155 grades), it was noted that $76.84 \%$ of learners successfully completed courses with a grade of C- or better. A higher level of success was noted among the 950 UC students matriculated in online undergraduate degree programs(two associate and five baccalaureate degrees) taking 100 and 200 level online courses during this same time period; $85.15 \%$ of these learners successfully completed courses.

There are various reasons for this high level of success among this group of online learners, including learner attributes and motivation. These students are often pursuing a degree which is related to their 
current job and is necessary to retain their position, or move ahead on a pay scale. For example, the online associate's degree in Early Childhood Education serves Head Start teachers who are mandated by federal law to possess an associate's degree. In addition, the University's most recent student course evaluations as well as internal and external surveys reveal a number of educational practices that are contributing to student success. These are noted in the following discussion.

\section{STRATEGIC FRAMEWORK FOR SUCCESS}

The design and implementation of all academic programs, distance learning and campus-based, is guided by UC|21, the University's strategic plan. Thus, students enrolled in online programs can expect a solid curriculum, faculty with expertise in the area of study, and services focused on providing the same level of support provided to students in campus-based programs, throughout their academic experience.

A number of strategies contribute to the success of UC's distance learning efforts. This includes a wideranging network, within and outside the University, that builds on institutional infrastructure-academic, technical, faculty and student support, and administrative. Notable are some examples of these strategies and their alignment with Sloan-C Pillars of Success.

\section{A. Learning Effectiveness}

The initiation of all distance learning courses and programs begin on the academic side of the institution. Faculty involved in each academic program give careful thought to curriculum and instructional design to ensure high quality learning experiences for students. This process includes an assessment of the instructional needs of learners and context (i.e., learner population, learner history, learning styles, and technical support and equipment.) Strategies support learning goals and objectives that are clear and performance-oriented and promote learner success through clearly communicated objectives, feedback, and assessment of learning. Design of materials is based on instructional strategy, content, media to support online education, and assessment for learner outcomes and evaluation of the instruction. Faculty members are involved in each academic program as the content and curriculum experts and, depending on their online experience, as instructional designers.

The Faculty Technology Resources Center (FTRC) http://ftrc.uc.edu provides expert instruction, support, and equipment access for the use of instructional technologies in teaching, including multimedia development tools and Blackboard training and support.

The Center for the Enhancement of Teaching and Learning (CET\&L) http://www.uc.edu/cetl/ serves faculty and teaching assistants via a variety of programs to support effective teaching and learning. In collaboration with technology experts from FTRC and experienced UC educators, CET\&L provides attendees with interactive (and often hands-on) experiences to learn new skills and ideas that can be implemented immediately in their course of instruction. Last year there were 1,293 registrants in 131 workshops pertaining to pedagogy (such as Inquiry-Guided Learning), and effective use of technology in education and distance learning (best practices for teaching online, Web 2.0 for educators, and others).

\section{B. Scale}

The University provides quality online programming where there are market opportunities that capitalize on the institution's academic/intellectual strengths, and efforts are congruent with enrollment management imperatives. Program planning includes various levels of review and/or endorsement 
processes to ensure that offerings are consistent with the university's strategic plan and appropriately resourced. Thus, colleges and programs work collaboratively with university units to develop and offer high quality online learning opportunities, while at the same time ensuring program viability and cost efficiency. Strategies to maintain costs, while not affect quality, include leveraging internal and external resources and expertise.

- $\quad$ CET\&L - workshops, peer consulting, pedagogy priorities, teaching/learning resources, etc.

- FTRC - teaching with technology, instructional resources, 24/7 Help Desk, Blackboard online course management

- University Libraries - teaching and learning resources

- Enrollment Management and Student Services — advising, orientation (technical and program), tutoring, registration, admission

- Faculty and distance learning administrative expertise - one-on-one consultations

- Ohio Learning Network - sponsored by the Ohio Board of Regents, this statewide initiative supports faculty, student, administrative resources; professional networks, professional development; funding opportunities

Online classes involve a significant amount of student-faculty interaction. Enrollment is limited according to the course content and support systems available to prevent faculty overload and ensure student success. Typically, a ratio of 1:20 up to 1:30 is used in online programs, with the addition of another course facilitator for each enrollment increment in a course (in general, one facilitator for each cohort of 20-30 students within a distance course).

\section{Access}

Consideration is given to every aspect of the distance learner's program — from initial admittance to graduation-working in an integrated way to maintain student engagement and successful academic progress. Student services and academic supports are designed to provide distance learners full access to a complete range of quality services and institutional resources. Placement tests for English and Math are online and online developmental coursework is available for undergraduates who need this additional support. Digital equity is a primary concern to programs serving older adults and every effort is made to ensure students still on dial-up have access to large files and videos via CD/DVDs. Blackboard and program orientation are often required before a student's first class, so every student has the tools for academic success. Other support systems take into consideration all aspects of the student's academic program, and reflect a team approach — involving stakeholders at the academic and institutional levelsto provide a level of consistency across programs, efficiencies within the institution, and to foster student success. Information regarding support services, access and contact information is conveyed through various venues, including in-person visits to potential cohorts, program information provided to new and prospective students via print materials and online via program, institutional websites, and virtual Open House webinars.

- Dedicated administrative and support staff (oversight, points of contact, etc.) for each online program

- Program information — print materials and online via program websites

- Institutional Information — in-person and online ( www.uc.edu/distance)

- Admission \& Registration - UC's OneStop online student services (www.onestop.uc.edu/) enables DLs to apply, register and pay online

- Tuition payment \& Financial Aid — online 
- Blackboard course management resources http://blackboard.uc.edu/webapps/portal/frameset.jsp?tab id=86_1 - online help functions available 24/7 (i.e., guides, tutorials, instructions for activating accounts, FAQ's) Telephone and e-mail support hours: Monday - Friday, 8:00 am - 12:00 am (midnight); Saturday, 12:00 pm - 6:00 pm; Sunday, 2:00 pm - 12:00 am (midnight)

- IT Help Desk http://www.uc.edu/ucit/helpdesk/default.asp - online, e-mail and via telephone. Hours: M-F, 7:00 a.m.-9:00 p.m.; Saturday \& Sunday, 8:00 a.m. - 9:00 p.m.

- Bookstore — online textbook services

- Academic support - e-tutoring; online access to UC's library system and databases/articles; advising and monitoring of student progress conducted at the academic unit/program level

- Student discounts - computer software; purchases facilitated online and via mail

\section{Faculty Satisfaction}

An academic administrator in each college oversees distance learning courses and online programs. This includes distance learning faculty development through a variety of venues: involvement of onsite experts within the college and University; fostering attendance at national and state conferences on technology in education; and workshops offered by specialty associations on distance learning. Faculty development is also available as needed on a one-to-one basis. Some colleges have further identified faculty leaders and staff liaisons for the support and expansion of technology infusion in pedagogy and instructional design and for the support and development of distance learning. Faculty often report the online teaching experience has improved or enhanced their face-to-face teaching.

The process for staffing online courses varies with the size of the program. Department and program heads assign faculty to all teaching assignments and include tenured faculty, tenure-track faculty, clinical faculty, and adjuncts. A faculty member's teaching load is determined in consultation with the head and can involve a split between traditional programs and online programs. Facilitators and teaching assistants with specific roles may also be assigned to courses. These individuals function under direction of the lead faculty member for the course, with greater emphasis placed on team-based instruction and online support services. This may involve serving as liaison to coordinate all aspects of online academic support services and personnel to maintain excellent student learning outcomes and program delivery quality.

Recruitment of faculty members, adjuncts, and teaching assistants includes an orientation to college and university resources and support; such as, the online course management system, technology expectations, online communication tools, pedagogy and online course development and centers/resources. Various resources contribute to supporting faculty and graduate teaching assistants in design, development and delivery of distance learning.

- Faculty leaders and staff liaisons in various colleges to promote and support expansion of technology infusion in pedagogy and instructional design

- Professional development opportunities and support via CET\&L, FTRC University Libraries, and onsite experts within colleges

- Compensation (If not part of regular workload)

- Distance learning seed grant opportunities

- Faculty institutes via the Faculty Development Council 


\section{E. Student Satisfaction}

"Place Students at the Center” is the first of five goals in the University's academic strategic plan, UC|21 (http://www.uc.edu/uc21/ataglance.html), and reflects the University's commitment to the academic success of each student. This student-centered philosophy emphasizes mechanisms that place priority on students' needs, a university-wide concept of one-stop service, creation of a 24/7 learning and social environment, and attract the highest-quality students while maintaining clear pathways for students who seek opportunity.

Although online students rarely meet program faculty and staff, they develop a rapport that is sustained from admission through graduation. Online students have access to a wide variety of online services and academic supports available to all UC students. Those students enrolled in online degree programs also benefit from supplemental program support. Based on feedback from undergraduate online learners via course evaluations and surveys, including the National Survey of Student Engagement (NSSE), students report high satisfaction with a variety of educational practices and entire educational experience at UC.

- Supportive institutional environment to help the student succeed academically

- Quality relationships with program faculty and staff

- Peer networking and support

- Prompt feedback from faculty on academic performance (in general, program policies indicate 24-48 hour turnaround time)

- Practices that challenge the student to do his/her best work

- Academic advising

\section{CONCLUSION}

Over 85 percent of students matriculated in online undergraduate degree programs successfully completed courses in Autumn Quarter 2008, with a grade of C- or higher. This high rate of success in online courses could be attributed to the variety of support available including University-wide services and programspecific student support as well as student motivation. In addition, the University of Cincinnati's strategic plan, UC|21, represents a commitment to distance education, now and in the future, and has focused attention on this growing population of students.

\section{ABOUT THE AUTHORS}

Dr. Melody Clark, Ed.D., has over 30 years of experience in higher education, ranging from administrator, student and educator. She is Director of Distance Learning in the Provost Office at the University of Cincinnati and serves as institutional liaison on matters pertaining to distance learning. Her professional experience at the University has included coordinating and administering distance education programming and operations to support growth and development of distance learning. Melody earned her doctorate in Education from the University of Cincinnati in 2003. Her scholarly activity is grounded in the field of Educational Foundations and she teaches a graduate course geared to improving instructional effectiveness in the University's online Master's in Education program offered to cohorts of Health Professionals. She has presented at national conferences, including WCET E-Learning in Higher Education and Distance Learning Administration regarding distance learning and support services for academic success.

Dr. Lisa Holstrom, Ed.D., has presented on distance education at various conferences around the United States, including the National Head Start Association's national conference, NHSA's technology 
conference, and National Association for the Education of Young Children's Professional Development Institute as an invited presenter with the Office of Head Start, on the topic of university/program partnerships. Lisa has written an article for Children and Families and Educational Technology, among other publications. After serving for 8 years as the director of the Early Childhood Learning Community (ECLC), one of the largest distance education degree programs at the University of Cincinnati, she is now supporting other distance education initiatives for the College of Education, Criminal Justice, and Human Services at the University of Cincinnati. She is Principal Investigator on several grants from the Office of Head Start which has funded the translation of the online associate and bachelor's degrees into Spanish for teachers serving in Migrant and Seasonal Worker programs.

Dr. Ann M. Millacci, Ed.D., earned her doctorate in Educational Administration from the University of Cincinnati in 1998. She received her M.S. and B.A. degrees from the State University of New York (SUNY) College at Buffalo. She has been a member of the Educational Leadership faculty since 2003. Dr. Millacci coordinates the distance learning master's degree program in Educational Leadership and teaches the two core Foundations of Educational Administration courses in the online program. She has over 20 years of experience in higher education administration having worked in the areas of admissions, research administration, finance, and evaluation and assessment. Dr. Millacci has presented at national conferences on distance education including the Annual Conference on Distance Teaching and Learning sponsored by the University of Wisconsin- Madison. 